\title{
Overview of the Development of Special Education in Tibetan Society
}

\author{
Bu Qiong, Miloň Potměšil
}

\begin{abstract}
The Tibetan nationality is one of the 55 minorities in China. Tibetan people are mainly distributed in the Tibet Autonomous Region, Qinghai Province, Gansu Province, Sichuan Province, Yunnan Province, and other regions, with a total population of about 6.4 million. Education for national minorities has always been an important component of Chinese education, while special education in Tibetan society is an important part of Chinese national education. In recent years, special education has been rapidly developed along with the establishment of special education schools in Tibetan areas, especially since 2000 and the proposal for, and implementation of, educational equality and balanced educational development in China. The paper applies a literature review, observational method, case analysis method, and simple descriptive statistical method to depict the Tibetan people's understanding of special education and the adaptation of different types of disability in Tibetan society before 2000 . What is more, it takes the Tibet Autonomous Region and Sichuan Tibetan Region as examples to introduce the development of special education schools among Tibetan people after 2000 and analyze basic information about timetabling and students' skill training in special education schools among Tibetan people. It concludes that there are problems, for instance, that special schools are far from meeting the demand for education for children with special needs, curricula in schools cannot meet the demands for disabled children's localized cultural and life skills, and disabled children's early intervention and disabled
\end{abstract}


teenagers' transition and settlement measures are extremely deficient in special education in Tibetan society.

Key words: Tibetan nationality, Special Education in Tibetan Society, Development of special education.

\section{Introduction}

In China, Tibetan people are mainly distributed in the Tibet Autonomous Region, Qinghai Province, Gansu Province, Sichuan Province, Yunnan Province, and other regions, with a total population of about 6.4 million. Some live on the Qinghai-Tibet Plateau, the Roof of the World, which is also a land of snow because of the snowy mountains all around. There are three ecological zones, including a rural area, pasturing area, and farming-pastoral region, with their own respective ways of production and working. Tibetan people have their own language and words, a traditional culture of long standing, and a religion, Tibetan Buddhism. From birth to death, most Tibetan people live a farming life or a herdsman's life. Simple production and labour skills are all learnt and inherited in practice. People consider that the purpose of school education is to educate children to pass exams, find an office job, and get rid of farmers' and herdsmen's lives controlled and timed by the sunlight. They do not understand what changes school education can bring to production and life in farming and stockbreeding areas, or they do not know the value and significance of school education for human survival and development. It is generally considered that it is unnecessary to enable disabled children to go to school, given such an understanding of school education. Especially before 2000, there were no schools for children with special needs. Disabled youngsters who could not enter general schools failed to obtain a school education. Since 2000, some special education schools have successively been established in Tibetan areas to meet the educational demands of a minority of children with special needs. Therefore, to know about the development of special education in Tibetan areas, it is necessary to know about special education among Tibetan people in two stages: before and after 2000. 


\section{Understanding of Special Education of People in Tibetan Areas}

\subsection{Special Education in Tibetan Society Before 2000}

Before 2000, "special education" was an unfamiliar concept for most people in Tibetan areas and there was not one special education school in these areas. Middle- and lowgrade physically disabled and mentally retarded children could study in general schools, but the schools failed to meet their special learning needs, so they could only adapt to the learning environment and conditions in the same way as general students did. In early childhood, blind, deaf, and seriously mentally retarded children might receive medical treatment and rehabilitation training. If the effect of the training was not good, rehabilitation training could only be done at home on his or her own initiative and there were no opportunities for them to go to school. Because of the lack of understanding of special education, neither systematic and normative special education diagnoses nor early intervention took place in Tibetan areas. Therefore, the development of special education was far behind that in inland and other minority regions.

\subsection{Social Adjustment Conditions of the Disabled in Tibetan areas}

Being religious, all Tibetan people have a very commendable tolerance and can fully respect and accept disabled children, while the disabled also have good self-recognition and social adaptation ability. Through long-term observation, it was discovered that no disabled people would be discriminated against too much in Tibetan society. Of course, different types of disabilities have different social adaptations.

The physically disabled. The physically disabled have normal language competence, so they can adapt to social communication, but different conditions may occur when they endeavour to take on ordinary production and labour tasks according to different types of physical disability and degrees of disability. They will generally acquire life skills that are adaptable to themselves according to their actual conditions. For instance, a person with a lower limb disability can learn hand sewing.

The deaf. Because of their lack of language competence, the deaf can only communicate with others with self-created gestures, leading to certain barriers when they communicate with intact people. If they have four limbs and their visual sense is normal, they can totally adapt to ordinary people's way of living. They can take part in any productive labour performed by ordinary people.

The blind. Without loss of language competence, the blind can communicate normally with ordinary people. But without visual perception, they cannot be occupied in production and labour like ordinary people and they even have certain difficulties in living an independent life. 
The mentally retarded. The middle- and low-grade mentally retarded can communicate with others smoothly and they can also adapt to production and labour that requires no great strength. The seriously mentally retarded cannot communicate with others normally or participate in the production and labour ordinary people work on, and they also have poor social adaptation.

From the above descriptions, it can be concluded that there was neither a diagnosis and rehabilitation organization nor community service for special education, nor a special education school before 2000 , so the disabled almost had no chance to go to school. However, they were very clearly recognized and helped by family members and others in the village with regard to social and life adaption.

\subsection{Special Education in Tibetan Society After 2000}

Since 2000, since the Ministry of Education, especially the Government of China, issued the "Special Education School Construction Plan in the Central and Western Regions during the $11^{\text {th }}$ Five-year Plan (2006-2010)", "National Medium and Long-term Education Reform and Development Plan Outline (2010-2020)", and "Special Education Promotion Plan (from 2014-2016)", Tibetan areas have successively built more than 10 special education schools, which have partially met Tibetan students' need for special education. The paper understands and analyzes the current development of Tibetan special education by the establishment of special education schools in the Tibet Autonomous Region and Ganzi Tibetan Autonomous Prefecture, Sichuan Province, and course design for deaf and blind students in the Ganzi special education schools.

\section{General Situation of Tibetan Special Education Schools}

In recent years, with the proposal of, and general attention to, educational equality and balanced development, education and special education in the regions inhabited by ethnic groups have seen unprecedented development opportunities. The Tibetan and Sichuan regions have successively built special education schools.

The Tibet Autonomous Region is a major province inhabited by Tibetans and a central area for the development of Tibetan culture, politics, and economy. According to the statistics, the number of all kinds of disabled youngsters (under 15 years old) in the Tibet Autonomous Region is 32,000. ${ }^{1}$ And since 2000, the Tibet Autonomous Region has

The data is from the Central Government's survey data in 1987 and the Tibet Autonomous Region Disabled Persons'Federation. 
successively built five special education schools. There are 656 students and 173 teachers and administrative staff members.

The Tibetan area in Sichuan Province is the central region of Kham in the traditional Tibetan area. As the main part of the Tibetan area in Sichuan Province, the Ganzi Tibetan Autonomous Prefecture has 1,889 disabled youngsters who volunteered to enrol in the record (not including those youngsters who were not certified as disabled) ${ }^{2}$ and built a special education school in 2009, with 102 students.

According to the number of disabled youngsters and special education schools in the two areas, since 2000, special education in Tibetan areas has undergone unprecedented development, but the existing special education schools can only meet the requirements of a small number of disabled youngsters.

\subsection{Tibetan Special Education School Timetable}

In the survey, we collected the timetables for deaf and blind students in the Ganzi special education schools (Table 1, Table 2).

Table 1

First-year hearing impairment class's spring 2015 timetable $^{3}$

\begin{tabular}{|c|c|c|c|c|c|c|}
\hline \multirow{6}{*}{ Morning } & class week & Monday & Tuesday & Wednesday & Thursday & Friday \\
\hline & The first period & Chinese & Tibetan & Mathematics & Mathematics & Chinese \\
\hline & Second period & Chinese & Tibetan & Mathematics & Mathematics & Reading class \\
\hline & \multicolumn{6}{|c|}{ Exercise between classes } \\
\hline & Third period & Mathematics & Mathematics & Chinese & Chinese & Mathematics \\
\hline & Fourth period & Mathematics & Chinese & Chinese & Chinese & Mathematics \\
\hline \multicolumn{7}{|c|}{ Lunch break } \\
\hline \multirow{4}{*}{ Afternoon } & Fifth period & Rhythm & Life skills & Reading class & Communication & Interest class \\
\hline & Sixth period & Rhythm & Art & Reading class & Communication & Interest class \\
\hline & \multicolumn{6}{|l|}{ Eye exercises } \\
\hline & Seventh period & $\begin{array}{l}\text { Ideological and } \\
\text { moral character }\end{array}$ & Art & $\begin{array}{l}\text { Physical } \\
\text { education }\end{array}$ & $\begin{array}{l}\text { Ideological and } \\
\text { moral character }\end{array}$ & Interest class \\
\hline Cleaning & \multicolumn{6}{|l|}{ Class is over } \\
\hline $\begin{array}{l}\text { Evening } \\
\text { self-study }\end{array}$ & Ninth period & Class meeting & $\begin{array}{l}\text { Self-study } \\
\text { courses }\end{array}$ & Writing class & Safety education & Class activity \\
\hline
\end{tabular}

2 The data is from the Ganzi Tibetan Autonomous Prefecture Disabled Persons' Federation in 2014.

3 The data is from the Ganzi special education school. 
Table 2

Fig. 2-1a Visual impairment class's spring 2015 timetable $^{4}$

\begin{tabular}{|c|c|c|c|c|c|c|}
\hline \multirow{6}{*}{ Morning } & class & Monday & Tuesday & Wednesday & Thursday & Friday \\
\hline & First period & Chinese & Chinese & Mathematics & Chinese & Tibetan \\
\hline & Second period & Chinese & Chinese & Mathematics & Mathematics & Chinese \\
\hline & \multicolumn{6}{|c|}{ Exercise between classes } \\
\hline & Third period & Mathematics & Mathematics & Chinese & Music & Chinese \\
\hline & Fourth period & Mathematics & Rehabilitation & Chinese & Music & Mathematics \\
\hline \multicolumn{7}{|l|}{ Lunch break } \\
\hline \multirow{4}{*}{ Afternoon } & Fifth period & Life skills & Mathematics & Art & $\begin{array}{l}\text { Physical } \\
\text { education }\end{array}$ & Interest class \\
\hline & Sixth period & Tibetan & $\begin{array}{l}\text { Ideological and } \\
\text { moral character }\end{array}$ & Art & $\begin{array}{l}\text { Physical } \\
\text { education }\end{array}$ & Interest class \\
\hline & \multicolumn{6}{|l|}{ Eye exercises } \\
\hline & Seventh period & Activity & $\begin{array}{l}\text { Ideological and } \\
\text { moral character }\end{array}$ & Physical exercise & Rehabilitation & Interest class \\
\hline Cleaning & \multicolumn{6}{|l|}{ Class is over } \\
\hline $\begin{array}{l}\text { Evening } \\
\text { self-study }\end{array}$ & Ninth period & Class meeting & Writing & Safety education & Self-study & Class activity \\
\hline
\end{tabular}

These timetables reflect the basic concept and special education value orientation of curriculum design in the current Tibetan special education schools, to a large extent, and fully indicate the developmental situation of Tibetan special education.

\section{Fig. 1 and 2}

\section{Visual impairment class's spring 2015 timetable $^{5}$}

First-year hearing impairment class's kinds of courses

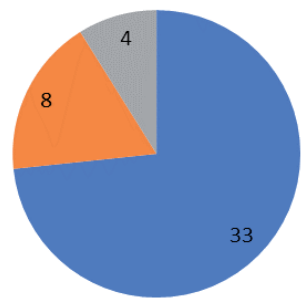

- cultural knowledge courses

- living habits and social interaction courses

- living and production skills and specialized courses

4 The data is from the Ganzi special education school.

5 The data is from the Ganzi special education school. 
Visual impairment class's kinds of courses

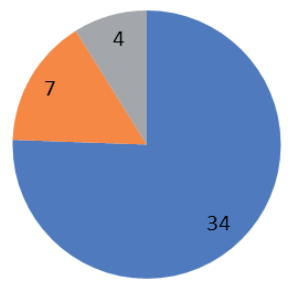

- cultural knowledge courses

- living habits and social interaction courses

- living and production skills and specialized courses

By analyzing Fig. 1 and Fig. 2, we can learn that there are three kinds of courses for $90 \%$ of the special needs children from farming and stockbreeding areas in Tibetan special education schools: (1) cultural knowledge courses which include languages, maths, science, and other basic knowledge, accounting for $73.3 \%$ (Fig. 1) and $75.6 \%$ (Fig. 2) of the total number of courses; (2) living habits and social interaction courses which aim to cultivate students' living etiquette, health habits, and communication methods and abilities, accounting for $17.8 \%$ (Fig. 1) and $15.5 \%$ (Fig. 2) of the total number of courses, and (3) living and production skills and specialized courses which aim at helping students study survival skills by preparing for their own conditions in their future life, accounting for $8.9 \%$ (Fig. 1) and $8.9 \%$ (Fig. 2) of the total number of courses.

\subsection{Cultivation of Skills for Students in Tibetan Special Education Schools}

Special schools in Tibetan areas are only responsible for compulsory education. After the students complete this education, only a few of them will continue their studies in vocational schools or universities. But more students will have to face the difficulties of transition and placement. So it is necessary to stress the importance of living and production skills and specialized courses. According to the different types of disabled students, many special schools in Tibetan areas have opened some skills courses by combining local cultural and social service requirements, such as blind massage for the blind, thangka painting and tailoring for deaf students, and vocal music, musical instruments, and dance for talented students, which can help them obtain some skills for their future life. 


\section{Conclusions}

By analyzing the development of Tibetan special education after 2000, we can draw three conclusions, as below:

(1) the government pays significant attention to the development of Tibetan special education, so more and more children with special needs will get a relatively fair education. But the few special education schools are far from being able to meet the requirements of all the children with special needs;

(2) although the courses in the Tibetan special education schools meet the national, local, and school-based requirements, education in the traditional culture still fails to be fully utilized and sufficient attention fails to be given to the local life of children with special needs;

(3) although special education schools help children with special needs finish compulsory education, there is still no solution for them to transit after early intervention and special education.

Finally, I can state that Tibetan special education should pay more attention to children with special needs to help them adapt to the local life and respect local people's educational needs according to the beliefs and values of the local community. But the national government policy does not take the local Tibetan needs into account.

\section{Acknowledgement}

This research was supported by the grant SDYWH1404 for Key Research of Philosophy and Social Sciences in the Sichuan Province Multicultural Research Centre and IGA PdF_2016_022.

\section{References}

Chen Q. M. (2011). Analysis of the current situation and problems of special education in Sichuan Tibetan. Journal of Sichuan university for nationalities, 20(5).

Dai G. Y. (2004). Research on Teacher Training of Special Education in West China. Chinese Journal of Special Education, 11.

Dai H., (2007). A Study of the Present Situation and Development Strategies of Special Education in Tibet. Journal of Research on Education for Ethnic Minorities, 3.

Ge CH \& Xie YH. (2014). The Influence of Religious Values on Tibetan Deaf Identity. Journal of Suihua University, 7.

Li H. et al. (2013). A Cognitive Study of Metaphor and Metonymy of Time in Tibetan Gesture Language. Journal of Minzu University of China (Philosophy and Social Sciences Edition), 6. 
Li J. (2013). Consideration of Tibetan Special Education Teachers Training. Master's Thesis.

Li J. (2013). Reflections on the Professional Development of Special Education in Colleges and Universities in Tibet. Journal of Suihua University, 4.

Mei Z. H. (2013). Tibet special education teacher training situation analysis. Tibetan education, 3.

She W. B. (2014). Exploring and Analyzing the Three Elements Model on Vocational Education of Disable Students Based on the Observation of Disabled Students in Sichuan Special Education School. Adult Education, 3.

She W. B. (2014). Investigation and Reflection of Special Education in Sichuan Ethnic Areas. Journal of Ezhou university, 12.

Shen, R. H. (2014). Research on Relationship Model of Social Adaptation. Social Support and Life Satisfaction of Tibetan Hearing Loss Children. Journal of Chongqing Normal University (Natural Science), 2.

Suo Q. \& Sun W. Z. (2013). Tibetan sign language development so that more Tibetan deaf barrierfree communication. Ethnic and religious.

Wu Ch. Y., Mao Y. L. (2014). Huang H., On the Development of Special Education School in Minority Areas. Journal of Sichuan University for Nationalities, 5.

Zhao X. Ch. (2014). Initial Research on Tibet Sign Language: Talk about Sign Language Work of Ethnic Minorities in China as Well. Tibetan Studies, 2.

Zhong J. H., Han P., Gao X. \& He Ch. (2011). On Tibetan-Language Braille and Its Abbreviations. Chinese Journal of Special Education (Monthly), 10.

\section{Contacts:}

Prof. PhDr. PaedDr. Miloň Potměšil, Ph.D.

Mgr. Bu Qiong, Ph.D.

Institute of Special Education Studies

Faculty of Education, Palacký University in Olomouc

Žižkovo nám. 5, 77140 Olomouc, Czech Republic

E-mails: milon.potmesil@upol.cz; 120589522@qq.com 